\title{
Socio-Cultural Problems of Urinary Fistula Patients Admitted at Dhaka Medical College and Hospital, Bangladesh
}

\author{
Murshida Begum ${ }^{1 *}$, Mohammad Shahinoor Islam² ${ }^{2}$ Shafayatul Kabir ${ }^{3}$ and Rubana Kaiser ${ }^{4}$ \\ ${ }^{1}$ Research Assistant, ICDDRB, Bangladesh \\ ${ }^{2}$ Dental Officer, SOJAG, Bangladesh \\ ${ }^{3}$ Medical Officer, Dhaka Medical College and Hospital, Bangladesh \\ ${ }^{4}$ Medical Officer, Dhaka Ahsania Mission, DNCC, Bangladesh
}

Submission: October 02, 2020; Published: October 08, 2020

*Corresponding author: Murshida Begum, Research Assistant, ICDDRB, Bangladeshs

\section{Abstarct}

Introduction: Urinary fistula is a maternal morbidity condition, which occurs in some middle and low-income countries, caused by prolonged obstructed labor that results in a hole between the vagina and the bladder or rectum through which urine or feces leak. Unrepaired fistula can lead to lifelong ostracism, stigma, and shame. Urinary fistula is both preventable and treatable, but women in these countries experience delays in seeking repair due to a number of factors including awareness of their condition as well as the potential for treatment, resources necessary for seeking care, lack of skilled fistula surgeons, and long hospital waiting times. This study aimed to find the social-cultural problems of women living with urinary fistula.

Methods: For this qualitative study, data were collected from fistula unit at Dhaka medical college and hospital. A total of 24 persons from the hospital were interviewed. Among them, in-depth interview was taken 10 respondents, 2 focus group discussion of the respondents husband and relatives and key informants (2 gynecologist and 2 nurses) interview was taken respondent service providers. Purposive sampling technique was used to collect data. Data was collected within the time period of 15th may 2015 to 15th October 2015. After collection data it was checked, coding and verified for consistency and reliability.

Results: The hospital based qualitative study was carried out in order to find the socio-cultural problems of urinary fistula patients. The findings of this study, the majority of the respondents in this study reported the following as possible causes: prolonged and complicated labour, early marriage, female genital mutilation, illiteracy, poverty and poor obstetric care. Age at marriage seems to be an important factor responsible for predisposing women to victims in Bangladesh.

Conclusion: Living with fistula reveals women's day-to-day experiences of social discrimination and loss of control due to incontinence and odor. Women experience of living with fistula was influenced by perceptions of people around them. In the eyes of these people, women who leak urine were of less value since they were not capable of carrying out ascribed social roles.

Keywords: Urinary fistula; Social-cultural problems; living with fistula; Bangladesh

\section{Introduction}

Women with Obstetric fistula in developing countries are mostly poor, malnourished, lack basic education and live in rural areas. They are also mostly rejected by their husband's family and/ or immediately divorced as a result of stigmatizing condition of obstetric fistula [1]. Globally, 99 per cent of the 289,000 maternal deaths are in low income countries. For each maternal death, 15 to 30 other women are left with serious morbidities including genital fistula, a preventable condition and treatable condition [2]. In Bangladesh, a few studies have reported the consequences of acute maternal morbidities [3]. The Bangladesh national estimate reflects that nearly 8.76 million women have been suffering from chronic morbidities like vesico vaginal fistula, recto vaginal fistula, uterine prolapse, dyspareunia, hemorrhoids and associated physical and social disabilities [4]. Although it is known that obstetric fistula (both vesico-vaginal and rectovaginal) occurs 
among women in Bangladesh, not much is known. In Bangladesh, the practice of allowing village attendants to assist with the delivery is widely accepted in the community. Most village attendants are untrained, and when complications ensue, some attempt is made to seek care at the health center. Utilization of antenatal services is also poor. Most mothers in Bangladesh do not receive antenatal care.

\section{Methodology}

This is a hospital based qualitative study.

\section{In-depth interview}

a) Ten urinary fistula patients were taken for these interview

b) The purpose of these interviews is to get information about the social, economic, environmental and cultural factors that might be responsible for the occurrence of fistula.

\section{Focus group discussion}

a) 2 FGD were conducted to the husband of the patients and the family members of the patient

b) Each group have 5 members

c) Purpose of these interviews is to get_their views and knowledge on urinary fistula patients

\section{Key informants}

a) Was conducted an interview of the service providers-2 Gynecologist and 2 nurse

b) Purpose of these interviews is to get their views on service provisioning for the fistula patients and validating the social and cultural factors responsible for fistula identification at the society.

c) To have their suggestions for future directions

Study area: The Study area was conducted at Dhaka Medical College and Hospital.

Study period: This study started with the approval of the research proposal firm the department of development studies of NSU. Although the tentative period is May 2015 to October 2015. It approximately requires 6 months of data collection, analysis, reporting along with approval from the university.

Data collection tools: In total three tools were used for collecting data. The tools was first developed and then reviewed by the experts. All the tools were field-tested. Consultants and trained health staff with medical and social science background collected information through. in-depth interviews and FGD and key informants. Below is a list of the tools employed:

a) In-depth interview questionnaire for the fistula patient

b) FGD Guideline: A guideline was developed and used for conduction of FGD with the husband of the patients and relatives

c) Key Informants: Interview was taken service providers of the urinary fistula patients

\section{Inclusion Criteria}

a) Admitted patients of urinary fistula and their age was 16-40 years

b) Urinary fistula patients who was bearing first child labor

c) Urinary fistula patients who was bearing $2^{\text {nd }}$ child labor

\section{Exclusion Criteria}

a) Those patients was not interested to interview or refuse to participate in the interview session.

b) Urinary fistula patients who was aged 41 years or more

Sampling technique: Purposive sampling was used for the data collection.

Data management: After collection of the data it was checked and rechecked and coded.

Quality control: Before finalization survey instruments a pretest of the questionnaire was conducted. Every day after collection of data it was checked again to confirm the collected data correct. The researcher was collect the data maintaining respondent's culture, attitude and regular practice so that respondents feel comfortable to provide information willingly. A triangulation of a questionnaire, focus group discussion and Indepth interview (IDI) was made to increase to reliability of the data.

\section{Result}

The hospital based qualitative study was carried out in order to find the socio-cultural problems of urinary fistula patients. The data for this study was collected from Dhaka medical college and hospital. A total of 22 persons from the hospital were interviewed. Among them, 10 were fistula patients, 5 woman had received post-operative care and 5 women had received care. 7 persons among them 2 husbands and 5five relatives of the patients, and 2 gynecologists and 2 nurse were interviewed.

\section{Interviewed of the respondents}

Table 1: Interviewed of the respondents.

\begin{tabular}{|c|c|}
\hline Respondents & Frequency \\
\hline urinary fistula patients & 10 \\
\hline Relatives of the patients & 6 \\
\hline Husband of the patients & 2 \\
\hline Gynecologist & 2 \\
\hline Nurses & 2 \\
\hline Total & 22 \\
\hline
\end{tabular}


The data which was obtained and analysed to find their sociocultural problems, their knowledge about their disease condition and their life style. The findings of the study are explained below (Table 1).

\section{Status of urinary fistula patients}

Socio-demographic profile: Socio demographic characteristics are a major parameter to differentiate the samples. A huge number of females suffer from-urinary fistula but comes different social classes. This socio demographic characteristic can be divided by age, sex, marital status, economical status, education of the family size, residence and religions etc (Table 2).

Table 2: Socio demographic characteristics of the participants (age).

\begin{tabular}{|c|c|}
\hline Age & No of Participants \\
\hline $16-23 y r s$ & 1 \\
\hline $24-31 y r s$ & 5 \\
\hline $32-40 y r s$ & 4 \\
\hline
\end{tabular}

Areas of origin: The respondents in this study came from a rural areas. The majority of the respondents were from rural areas and the remaining one came from urban area of faridpur city. The findings of this study all the women affected with Vesico-Vaginal Fistula come from rural areas where there is a high level of illiteracy, poverty, inadequate health care and obstetric facilities. Rural areas also face the problems of strong hold to traditional practices.

Socio-economic and educational background: The findings of this study indicated that all the respondents came from educationally and socio-economically disadvantaged background. The majority of the respondents are from extremely poor families and did not complete their elementary school education. Women who suffer from obstetric fistula tend to be impoverished, malnourished, lack basic education. Therefore, illiteracy prevents victims from having knowledge about their health condition and it also blinds them to understand the basic treatment and management involved in the condition Vesico-Vaginal Fistula. Once VVF occur it is difficult to heal on its own, therefore surgical repair is necessary. However, due to the extreme poverty, parents and victims alike face the difficulty of raising fund for the treatment. Condition of poverty has a direct effect on the quality and quantity of food intake of most of the patients afflicted with VVF.

Marital age of respondents: The findings in this study age at marriage of significant percentage of urinary fistula victims ranged between 11 and 18 years. , women often marry as adolescents, sometimes as young as 10 years of age, and may become pregnant immediately thereafter marriage, before their pelvises are not fully developed for childbearing (Table 3).
Table 3: Marital age of respondents.

\begin{tabular}{|c|c|}
\hline Marital Age & No of Respondents \\
\hline $11-14 y \mathrm{rs}$ & 4 \\
\hline $15-18 \mathrm{yrs}$ & 6 \\
\hline
\end{tabular}

In this study, the age at which victims developed fistula range from 11 to 19 years. 8 of the respondents were of the opinion that if they had delayed marriage until when they were old and matured enough to carry pregnancy, they probably would not have been in their condition. Despite the fact that many women spoke of experiences of lacking support from their husbands, few reported receiving support from them "Yes, my husband supported me. He provided me with cash so that I could seek fistula treatment" (shirin, 25 years, 6 month with fistula).

One of the respondents, 27 years old NURJAHAN: is quoted as saying "pregnancy is for those who are old enough to carry it, if I did not marry at age 11, I would not engage in sex, and I would not be pregnant, look at me I still look like a girl who should not think about getting pregnant until the next 10 years. Marrying at early age is not a good practice".

Another respondent Age 25 years Noor Aisha, in her words, she said, "How can a little child get pregnant and give birth to another little child? I was just 13 years old when my Uncle arranged my marriage. My body was not ready for sexual activities. When I got pregnant, the pregnancy was almost bigger than my whole body. My pelvic bones and "private part" were still very small. I could not push the baby out for 3days. When the baby came out the 3 day, it already died. After some weeks, I could not hold my urine. I became isolated and humiliated by everybody especially my in-laws and after that my husband divorced me. If I was mature and old enough before getting pregnant, my pelvic bones and "private part" would have been big enough and I would be able push the baby out without difficulty".

\section{Marital status of respondents (Table 4)}

Table 4: Marital status of respondents.

\begin{tabular}{|c|c|}
\hline Stay with husband & 1 \\
\hline Stay with husband but separated & 3 \\
\hline Divorced & 4 \\
\hline Widow & 2 \\
\hline
\end{tabular}

\section{Discussion}

World Health Organisation (2006) reports that skilled care before and after birth, and particularly during labour can make the difference between life and death for women and their babies and can help to prevent obstetric fistula. In this study, majority of the respondents reported they did not visit ante-natal clinic. 
One of the respondents ages 30 Sabera said that. "I could not visit the clinic when I was pregnant because, there is no clinic in my village. My laws not allowing visit to City clinic or hospital. I don't have parents so I cannot afford transportation to the city, and we have traditional midwives around, and there is no charge for their services". It is also observed in this study that there is a prolonged lag between onset of fistula and first visit to the hospital when asked about the time waited before seeking medical treatment, 5 of the participants responded they did not seek medical intervention immediately. One of the participants, Jarina (age 40) said, "I did not know where and who to inform when I started wetting my cloths. It was very embarrassing and shameful. May be if there is a clinic around, I would have gone" The reason for not seeking medical attention immediately may be attributed to the fact that fistula repair facilities are inaccessible to victims, also VVF patients are stigmatized and ostracized by the society, therefore, they would rather bear the shame and pain in isolation. Another crucial reason that rural people often repose confidence in their traditional healers who handle their cases with empathy.

\section{Attribution to Causes of Urinary Fistula}

In this study six of the respondents said that they were suffer prolonged and complicated labour at their first pregnancy. Due to delay delivery baby come out dead.

\section{Psycho-social problems}

The findings of this study physical pains and consequences of continuous passage of urine and smell, victims face sociopsychological consequences which make their conditions more burdensome and unbearable. These conditions further complicate their physical problems. 4 of the respondents, said "They are very sad because their husband asked to go back to their parents' house and divorced them because they useless to him sexually and also because body smelt of urine all the time, everybody is running away from the moment they know about condition".

\section{Years old Fatima}

was very emotional when she said, "Apart from my uncontrollable passage of urine, I faced a lot of rejection from everybody around me. When my husband realised, this sickness will not go away, he took me back to my father's house and asked me not to come back. Most of the time I locked myself up in the room without talking to anybody and eating limited food and less drinking water".

\section{In Aisha's (25 yrs) words}

"If people accept you with your condition, it can help to solve the problem. As for me, I have nobody to turn to. My husband divorce me when I was pregnant, I already lost my parents when I was very little. My uncle who gave me out in marriage also abandoned me. Everybody who knows my condition treats me like as burden. Life is very hard for me".

Also WHO (2006) reports that "since the obstructed labour usually results in stillbirth, the victim will not be able to have a child of her own. The future thus becomes disastrous for both the wife and the husband. Faced with this situation, many men find it easier to rid themselves of their damaged wives and seek other, fertile, spouses". In this study, 3 of the respondents bearing fistula after $2^{\text {nd }}$ child labour and other of the respondent bearing fistula after $1^{\text {st }}$ child labour.6 had still births and are unsure whether or not they will be able to raise a child again in future.

\section{One respondent $27 y r s$ old Nurjahan said}

"how can I ever be happy again in my life, with no child or husband"? Another psycho-social consequence observed in this study is the inability of the victims to make a living, many women living with VVF find it difficult to meet their daily financial demands. This is due to the fact that, they are not fit enough to get a sustainable job. Six of the respondent reported that no one will be willing to give them any job.

\section{One of the respondents, Aisha}

'responded on her state of economic production, "Before my sickness, I was buying fruits on the farm and selling in the market, but due to my condition, I don't even have the money to buy the fruits. I don't think anyone would want to buy fruits from me with my condition. This is so painful". Apart from the social isolation from both husband and the society alike. INFO project (2006) observed that many women with VVF live for years without financial or social support. Many fall into extreme poverty, the true situation of women afflicted with the disease. Depression and loss of self -esteem are major psychological problems faced by victims of urinary fistula.

Psychological depression involves mood swing, anger, anxiety, distress, hypochondriasis and withdrawal. This sometimes affects people who suffer from a devastating damage or loss of a valuable possession. This is exactly the case of a VVF victim, thus their state of depression leading to withdrawal should not be surprising.

\section{Fatima said}

"sometimes, I wish I were not born... to die is even better than to be in this condition because no one wants to be with someone with this disease, I can't get a meaningful job. I can't meet like others. What is the point living? When I am alone and depressed, I sometimes think of committing suicide"!

\section{Street begging}

In this study two of the respondent's that they begged on the streets in order to make money. According to these respondents, this activity was the easiest and most common for people with any form of stigma or disability in Bangladesh.

\section{Accepting fate}

Apart from the financial hardship of finding food to eat, most victims of Urinary Fistula have resorted to fate. Majority of the respondents in this study came from an Islamic background, and since Islam's doctrine is based on a total submission to the will of Allah, whatever Allah wills, you cannot query. 


\section{One of the respondent Jarina said,}

"I am not alone in this condition; Allah is with me because he allowed this to happen to me". Whether religion or fate, a majority of Bangladeshis have the culture of attributing their misfortunes to divinity, by so doing, their pains and suffering are spiritually alleviated. Another of the respondents, Fatima said, "If I don't accept my condition the way it is, what would I do? The best thing I can do is to accept this as the will of my creator".

Another victim, Sabera was emotional when she said "out of all the women that I know, why is it that I am the only one with this sickness? That is my own fate!"

\section{Involving in religious activities}

Two of the respondents in this study reported that they cope with their disease by associating with prayer activities and believing in miracle from God. One of these jarina respondents said, "I learnt that when you go to mazar, they would be able to help you".

Age at marriage seems to be an important factor responsible for predisposing women to victims in Bangladesh. The average age of marriage and conception of respondents in this study was 20 and 25 respectively. Six UF victims interviewed at this period were of frail stature with narrow pelvic bones. By the time of child delivery, they usually face a prolonged and complicated labour often resulting in the death of the baby and subsequent incidence of UF. Their situation is more pathetic when the woman has previously had an internal organ infection due to harmful traditional practices such as circumcision or genital mutilation. Other contributory factors include poverty and illiteracy. This study points to a fact that UF victims in Bangladesh are often from rural, poor and illiterate backgrounds. As a matter of fact, majority of the respondents in this study came from a social and economic disadvantaged background. Poor people often live in rural areas where there is inaccessibility to basic social amenities, like good water, quality food, and education and so on. Poverty has an impact on the quality and quantity of food intake; hence UF victims often suffer from malnutrition leading to disproportionate and slow body development. Due to poverty also, some parents like to shift the financial responsibility of their female daughters to able to body men who are willing to marry them. This situation saves them the hassles of fending for their female children. Lack of skilled and obstetric care has also been identified in this study as a contributory factor to the prevalence of VVF in Bangladesh. Since a vast majority of the victims are rural dwellers, it becomes difficult for them to access health care while pregnant and at delivery period. Even when women develop fistula, it takes them a long time before receiving medical attention, usually present in the urban areas. While rural areas in Bangladesh lack adequate maternity care, poverty prevents UF victims from affording transportation and cost of treatment in the cities.
Most of the respondents in this study have indicated virtually all the after mentioned physical and psycho-social conditions; however, the psychosocial conditions were reported to be greatly significant in destroying their emotional well-being. Women suffering from the scourge of VVF are victims of their socialcultural circumstances; however, the same societal conditions which pre-expose them to this disease are not offering them the required social and emotional support to deal with their trauma. The moment victims report their VVF conditions, they are rejected, ostracised and treated as if they are not fit to remain in the "normal" society. With this situation, many of the victims are left to take care of themselves. The findings in this study reveal that all interviewees were married at the period of child delivery, but abandoned when they developed fistula. This is an indication that a majority of women suffering from VVF are only victims of their socio-cultural circumstances. It is thus demoralising to them that they suffer the pains of crimes they never committed. Depression and low self-esteem have been identified in this study as a major psychological effect often experienced by VVF victims. If not adequately and urgently attended to, many victims would end up committing suicide. This study was limited to 10 women affected by urinary fistula. Majority of the respondent not interested to discuss about their sexual life. They feel shy. It is likely that women who managed to seek care were those who received support from their relatives and communities, whereas those who could not come to the hospital had more severe negative experiences of living with fistula. Nevertheless, this study did not aim at transferability or generalizability of findings, but rather to understanding and shed light on how women experience living with fistula in Bangladesh.

\section{Conclusion}

This study unveils the day-to-day experience of social discrimination and loss of independent income of women living with fistula. Women who live with fistula are not able to assume ascribed socio-cultural responsibilities. They are a burden because they cannot contribute to the family earnings, cannot satisfy their husband's sexually, nor bear children. Therefore, in the eyes of the society they are of less value due to failure to carry out social and marital roles. Lack of society awareness about fistula and availability of treatment and issues related to fertility after fistula repair have contributed to the negative perceptions by societies about the affected women and in turn women's experience of social discrimination. Education programs through various sources to communities will help people understand about fistula including the nature of the condition and its cause so that women living with fistula are welcomed and receive fistula treatment and necessary social support.

\section{References}

1. Islam AI, Begum A (1992) A psycho-social study on genito-urinary fistula. Bangladesh Med Res Counc Bull 18(2): 82-94. 
2. Akhter HH, Chowdhury ME, Sen A (1996) A cross-sectional study on maternal morbidity in Bangladesh.

3. Begum A (1991) Urinary fistula: A continuing menace in the third world, paper was presented at the $13^{\text {th }}$ World Congress of the FIGO, held in Singapore.
4. Falk HC (1964) Urologic Injuries in Gynecology. In: (2 $2^{\text {nd }}$ edn), FA Davis Company, Philadelphia, USA.

\section{Your next submission with Juniper Publishers will reach you the below assets}

- Quality Editorial service

- Swift Peer Review

- Reprints availability

- E-prints Service

- Manuscript Podcast for convenient understanding

- Global attainment for your research

- Manuscript accessibility in different formats

( Pdf, E-pub, Full Tsext, Audio)

- Unceasing customer service

Track the below URL for one-step submission https://juniperpublishers.com/online-submission.php 